\title{
Developing a virtual driving simulator for educational purposes
}

\author{
İ. Öztel and C. Öz
}

\begin{abstract}
Analyzing traffic accidents, human behavior represents the most relevant problem; especially drivers' behavior. In this regard, driver education becomes essential. In our project, we present a simulator consisting of both software and hardware including, a steering wheel, a pedal system, a shift knob, a seat and a visual display. This system needs a virtual platform modeled using Google Sketchup-3D Modeling Program. We used a Unity Game Engine in order to enable the platform. Owing to this simulator, prospective drivers will be able to acquire experience in a virtual environment without the risks of the real world.

In the simulator, the driver is penalized for every infraction according to the Turkish traffic rules. For instance, if the driver runs a red light, then penalty points are given. If the driver does not follow traffic signalization, again the simulator penalizes the driver with penalty points.
\end{abstract}

Index Terms - Driving simulator, driver education, game programming, virtual reality, traffic accident prevention

\section{INTRODUCTION}

M ANY of the accidents that happen in traffic are due to human failure, vehicles, state of roads and signposts whose positions are inadequate. According to an analysis made by the "Republic of Turkey General Directorate of Highways", the most relevant factor is the human factor, especially drivers. The rate of accidents that occur because of drivers is approximately 90 percent (Table I) [1] and 1.24 million people die each year on the world's roads, according to the World Health Organization [2]. Moreover, according to OECD, the reported rate of accidents caused by young drivers in between the ages of 15 to 24 is 70 percent [3]. In this case, driver education becomes important, particularly for novice drivers. Traditionally, the novice driver education procedure is to have him/her drive in real traffic conditions. Of course, there are several risks every time the inexperienced driver is in this situation. In order to avoid those risks, driving simulators can be used effectively.

Simulators have been used for 50 years [4] for a wide range of purposes. One of which is driving. In vehicle simulators, not only the operation of cars can be simulated, but also of

İ. ÖZTEL, is with the Computer Engineering Department, Faculty of Computer and Information Sciences, Sakarya University, Sakarya, TURKEY. (e-mail: ioztel@ sakarya.edu.tr).

C. ÖZ, is with the Computer Engineering Department, Faculty of Computer and Information Sciences, Sakarya University, Sakarya, TURKEY. (e-mail: coz@sakarya.edu.tr). trucks, tanks, trains, planes, etc... In the 1970s, the first step was taken towards creating driving simulators [5] and they have developed rapidly in recent years [6]. Driving simulators may consist of various pieces of equipment differing from each other. For example, some simulators are controlled with a keyboard while others, with a steering wheel. Furthermore, a real car can be used as a simulator. A virtual display can sometimes be a monitor, sometimes a projector screen and sometimes a head mounted display. Driving simulators are categorized into three groups [7, 8]: low-level, mid-level, high-level. Generally, low-level simulators include a steering wheel, pedals and a computer, mid-level simulators have also a motion platform, a visual display and a computer or computers, high-level simulators use Stewart platform or a hexapod for sense of motion [9].

TABLE I

DefeCt Rates IN TRAFFIC ACCIDENTS BeTweEn 2007 AND 2011, In TURKEY [1]

\begin{tabular}{lllllll}
\hline \hline Year & Driver & Pedestrian & Passenger & $\begin{array}{c}\text { Total } \\
\text { Human } \\
\text { Factor }\end{array}$ & Vehicle & Road \\
\hline 2007 & 98.03 & 1.64 & 0.09 & 99.76 & 0.14 & 0.11 \\
2008 & 90.53 & 8.37 & 0.43 & 99.33 & 0.26 & 0.42 \\
2009 & 89.60 & 9.09 & 0.41 & 99.10 & 0.29 & 0.61 \\
2010 & 89.72 & 8.97 & 0.36 & 99.05 & 0.33 & 0.63 \\
2011 & 90.20 & 8.51 & 0.39 & 99.10 & 0.30 & 0.60
\end{tabular}

When we look at low-level simulators, the following studies appear; of course, these are some examples, not all of them. Hoe C. Lee et al. presented a study in which there was a lowmid driving simulator used to access older drivers' driving skills. Driver data were collected and analyzed. The conclusion of the study, as expected, was that older drivers' driving skills decrease with age [10]. David B. Kaber, et al. presented another study. The aim of the study was to determine the effects of cognitive, visual and simultaneous distractions on vehicle operational controls, such as breaking, and tactical, such as maneuvering. Tactical control needs more attention than operational control and visual and cognitive distractions increase driver workload were observed [11].

This section covers some examples of mid-level driving simulators. Jean-Michel Auberlet and his team conducted a study on the impact of perceptual treatments on drivers' behavior. The study included three sections. In the first section, simulators were used and two perceptual treatments were selected, i.e. rumble strips on both sides of the centerline and sealed shoulders, from the five tested to help drivers maintain lateral control when driving on rural crest vertical 
curves. Secondly, a diagnostic device was developed in order to evaluate the impact of perceptual treatments on the driver's performance, and installed upstream and downstream the field site. In the last step, data were collected from the simulator in two different circumstances, before and after the centerline rumble strips were installed. Finally, the comparison of the results showed that the rumble strips on both sides of the centerline and sealed shoulders were the most effective treatments. It was observed that using simulators is helpful in the road design process [12]. "A Driving Simulator Based on Video Game Technology" is another presented study in the group of mid-level simulators. The study aimed to use the simulator as a platform for studies of serious games and to use for traffic education such as ours [13]. Moohyun Cha, et al. presented another study at this level. In the study, motion data samples were collected from a real vehicle and transformed into data structures. The data were used in the virtual driving simulator for motion effects [14].

There also are many studies on high-level simulators. For example, Min Kyu Park, et al. performed a four sections study. First, they developed a motion platform and motion controller, then a new washout algorithm was developed to actualize the real motion of a vehicle to the workspace of the simulator. The next step was to develop a visual and audio system for a more realistic feeling [6]. Finally, for the communication and monitoring among the subsystems, an integration system was developed. Yi Tang at al. presented a simulation study that utilized a 6-DOF Stewart mechanism. The simulator was developed for heavy vehicles. The simulator's software collects data as signals from the interaction of the driver with the accelerator, the brake, etc... The data are identified by the software, and then outputted to the simulator's components. Owing to that, a system that ensures a real-time interaction closely similar to that of a real vehicle [15].

\section{THE DRIVING SIMULATOR}

Our developed virtual driving simulator includes software and hardware. The system is comprised of software installed onto a computer where the simulation program runs, and to a steering wheel with a driver's seat, a projector, and a projection screen.

The steering wheel is a Logitech G25 Racing Wheel, which contains a force feedback racing-wheel, a shifter module; gas, brake and clutch pedals. The steering wheel provides an authentic feel. The speed can be changed with the six-speed shifter and it has a push down reverse gear.

We used the Google Sketchup 3D Modeling Program to create the virtual environment, which is not imaginary. We used the central campus of Sakarya University for the modeling (for example Fig. 1 and Fig. 2). The campus was investigated on Google Earth. The buildings on campus were visited individually and photos were taken. In the next step, the buildings were created with the modeling program and suitable textures were added. Sketchup uses ".skp" file extensions, which are useless for the Unity. We needed ".fbx" file extensions for the buildings in the Unity Game Engine, so the 3D models (road, building, etc.) were exported with ".fbx" file extensions. The buildings were later combined with the game engine.

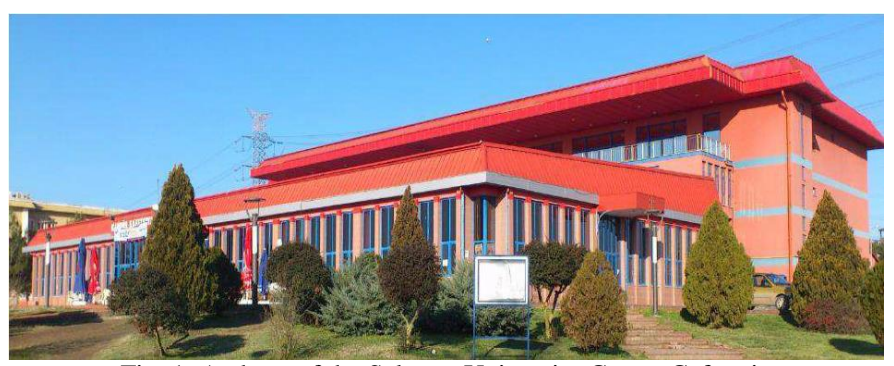

Fig. 1. A photo of the Sakarya University Center Cafeteria

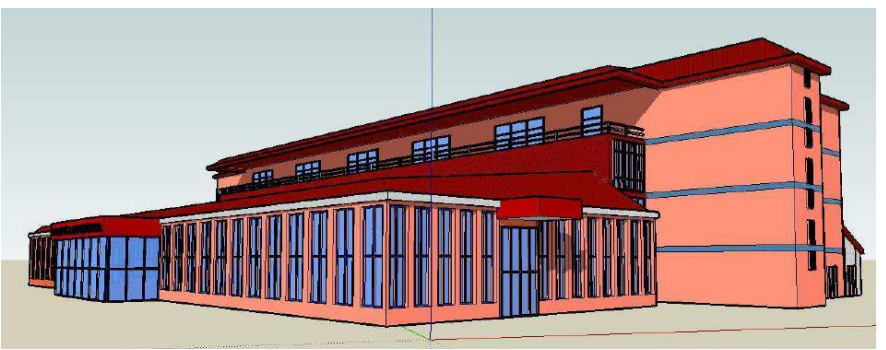

Fig. 2. A 3D model of the Sakarya University Center Cafeteria

The virtual original campus does not possess enough elements; therefore, a more complex scenario was required for driving education. For instance, signaling systems were installed at the junctions; new signs were added in the virtual campus according to the scenario. In addition, the simulator needed a car after the creation of the virtual environment. We used one of the ready to use cars from the Unity Asset Store car tutorial. The car was then, combined with virtual environment.

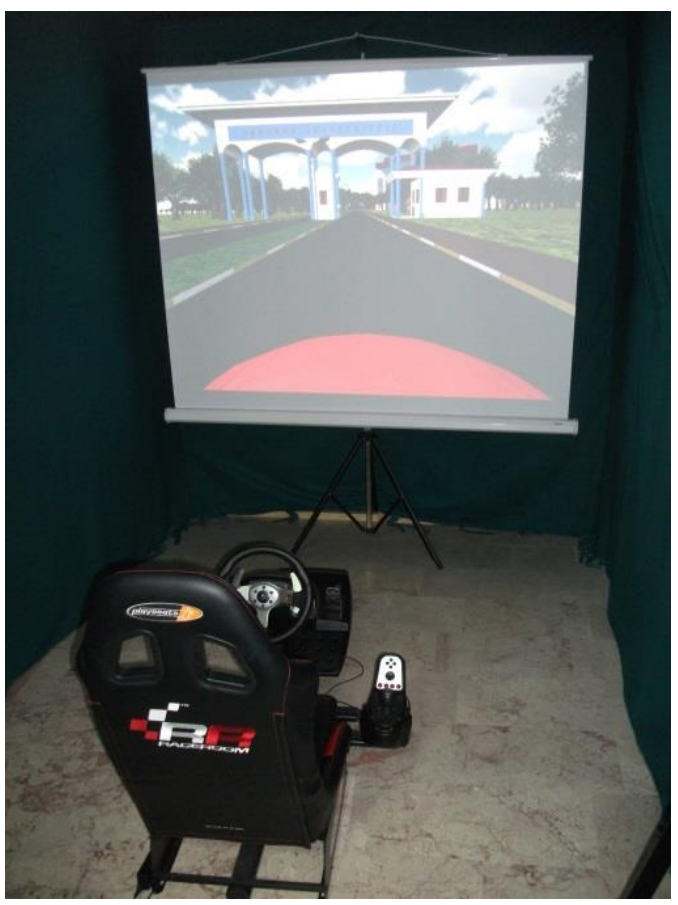

Fig. 3. The virtual driving simulator 


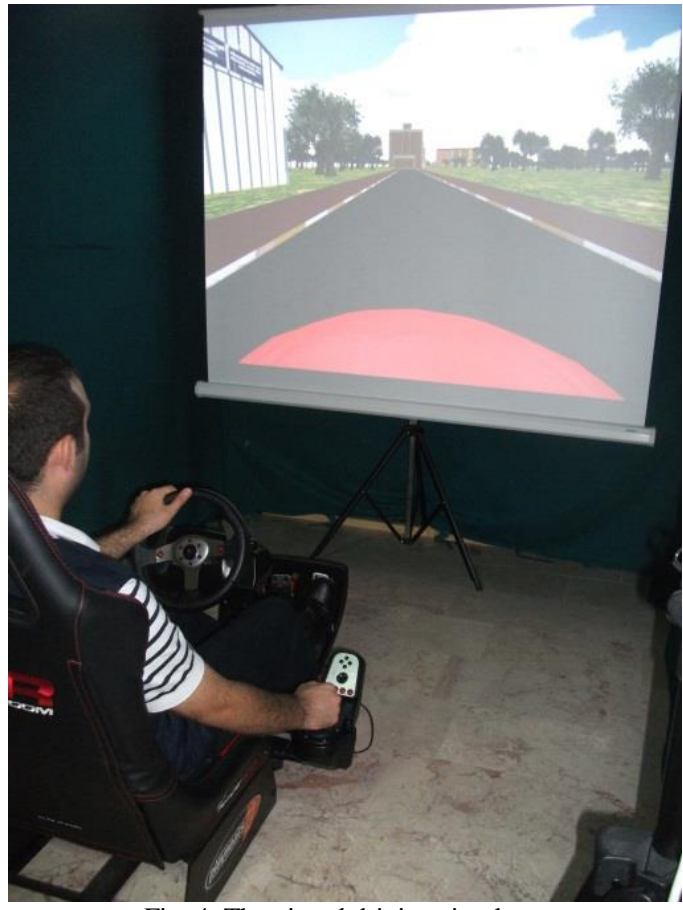

Fig. 4. The virtual driving simulator

There are penalty points for traffic violations in our scenario. The penalty points were determined by examining the guide, which is available on the website of Turkish National Police Traffic Services Department [16]. An example of such possible violations is "failure to comply with the rules of the red light", a twenty penalty points violation according to the penalties guide. Another example of a twenty penalty points is "failure to comply with traffic signs". Using those criteria, we determined all penalty points for each violation in the simulator.

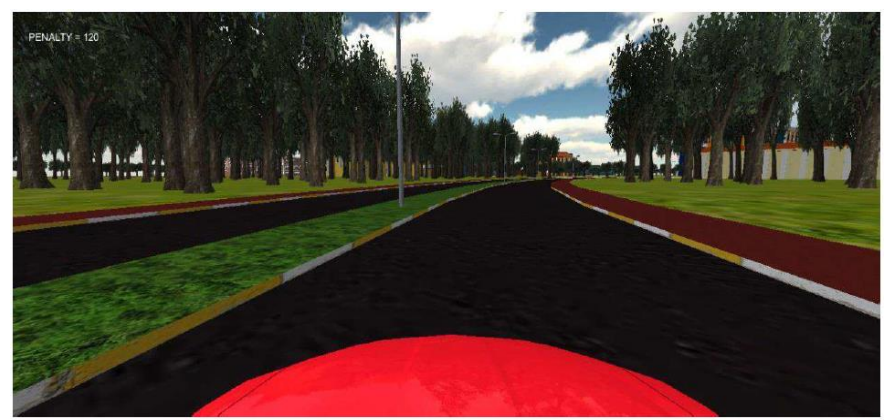

Fig. 5. An example view of the stage of the simulator

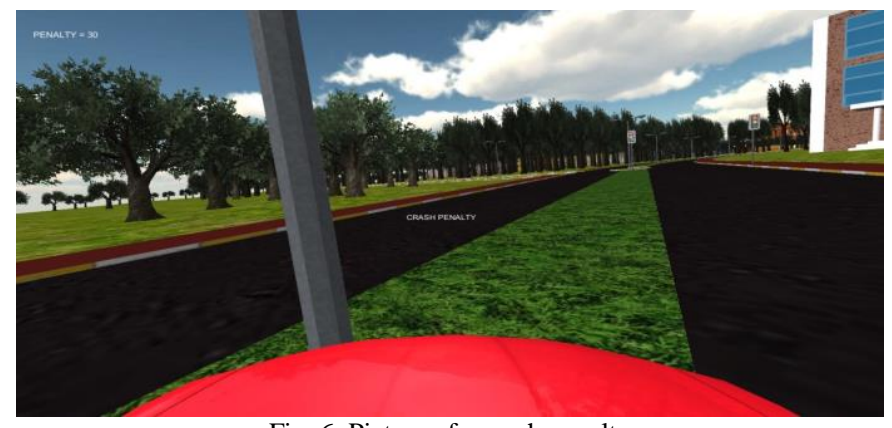

Fig. 6. Picture of a crash penalty

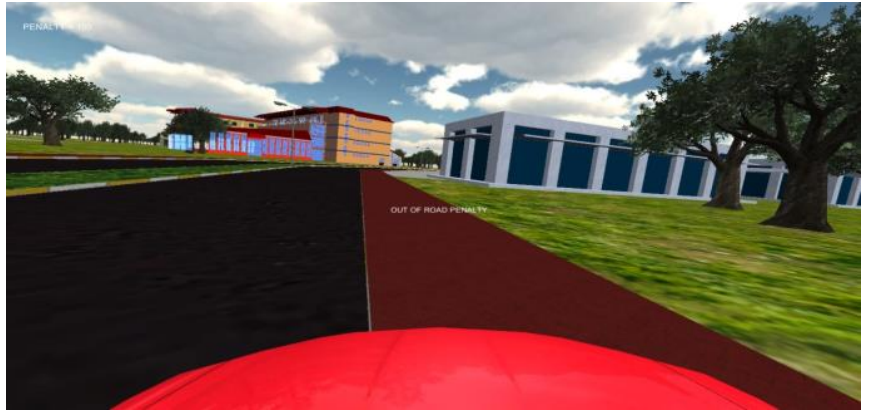

Fig. 7. Picture of an out of road penalty

Afterward, Java script was used to develop the penalization system. For example, if a driver runs a red light, the driver receives 20 penalty points. The penalties for the violation of the rules are given according to the Traffic Services Department penalty guide.

TABLE II

SOME OF PENALty Rules Violations ANd Their PENALty POINTS

\begin{tabular}{ll}
\multicolumn{1}{c}{ Rules } & Penalty Points \\
\hline Failure to comply with the rules of the red light & 20 \\
Exceeding the speed limit from \% 10 to 30\% & 10 \\
Driving detrimentally (go out of the way in the simulator) & 10 \\
Failure to comply with traffic signs & 20 \\
Parking where parking is prohibited & 10 \\
Exceeding the speed limit by more than 30\% & 15 \\
Failure to comply with the rules of right and left turn & 20
\end{tabular}

\section{CONCLUSION AND FUTURE WORKS}

In this study, a low cost virtual driving simulator was developed and established for the novice drivers' education. It uses a driver seat, a steering wheel, and a dashboard to provide a feeling similar to that of a real car. A projector is used to display the virtual driving environment on a screen positioned in front of the system. The software consists of a simulation program developed at the Unity, and 3D models created on Sketchup. We generated virtual scenarios intended as a driving education tool. Some scenarios are designed to teach and test the driver in "real" traffic conditions' simulations. The driving skills of the users, such as behavior at traffic light, speeding, and obedience to traffic signs, are improved and tested with the system. We determined penalty points for violations observing the Turkish traffic rules. Each user's error is penalized by the simulator's program according to the specified points and rules. Our simulator can be used to educate, improve driving skills, and teach traffic rules to novice drivers, using entertainment. The next goal is to add a few virtual cars and human beings with artificial intelligence, and engage participants in utilizing the system to determine its success.

\section{ACKNOWLEDGMENT}

The study is selected from International Symposium on Engineering Artificial Intelligent and Applications ISEAIA 2013 (Girne American University). 


\section{REFERENCES}

[1] Republic of Turkey General Directorate of Highways. (2011, August). Trafik kazaları özeti 2011 [Online]. Available: http://www.kgm.gov.tr/SiteCollectionDocuments/KGMdocuments/Traf ik/TrafikKazaOzet.pdf.

[2] World Health Organization. (2013, March). 10 facts on global road safety [Online]. Available: http://www.who.int/features/factfiles/roadsafety/en/.

[3] Organisation For Economic Co-Operation And Development. (2006, October). Young Drivers: The Road to Safety [Online]. Available: http://www.internationaltransportforum.org/jtrc/safety/YDpolicyBrief.p df.

[4] N. Goode, P.M. Salmon, M.G. Lenne, "Simulation-based Driver and Vehicle Crew Training: Applications, Efficacy and Future Directions," in Applied Ergonomics, vol. 44, 2013, pp. 435-444.

[5] B. Richter, "Driving Simulator Studies: The Influence of Vehicle Parameters on Safety in Critical Situations," in Society of Automotive Engineers, Warrendale, PA, 1975, pp. 91-99.

[6] M. K. Park, M. C. Lee, K. S. Yoo, K. Son, W. S. Yoo, M.C. Han, "Development of the PNU Vehicle Driving Simulator and Its Performance Evaluation," in International Conference on Robotics \& Automation, vol. 3, 2001, pp. 2325-2330.

[7] K. H. Siang, "Design and development of a virtual reality fixed base driving simulator," M.S. thesis, Dept. Mechanical Eng., Universiti Teknologi Malaysia; johor, Malaysia, 2008.

[8] J. Justice et al., "Interactive 3D application development using EON professional for creating 3D visualization," Irvine, CA, United States, 2010.

[9] N. Fouladinejad, N. Fouladinejad, M. K. Abd Jalil, J. M. Taib, "Modeling Virtual Driving Environment for a Driving Simulator," in IEEE International Conference on Control System, Computing and Engineering, pp. 27-32, doi: 10.1109/ICCSCE.2011.6190490.

[10] H. C. Lee, A. H. Lee, D. Cameron, C. Li-Tsang, "Using A Driving Simulator To Identify Older Drivers At Inflated Risk Of Motor Vehicle Crashes," in Journal of Safety Research, vol. 34, 2003, pp. 453-459.

[11] D. B. Kaber, Y. Liang, Y. Zhang, M. L. Rogers, S. Gangakhedkar, "Driver Performance Effects of Simultaneous Visual and Cognitive Distraction and Adaptation Behavior," in Transportation Research, vol. 15, 2012, pp. 491-501.

[12] J. Auberlet, M. Auberlet, F. Rosey, F. Anceaux, S. Aubin, P. Briand, M. Pacaux, P. Pacaux, P. Plainchault, "The Impact Of Perceptual Treatments On Driver's Behavior: From Driving Simulator Studies To Field Tests-First Results," in Accident Analysis \& Prevention, vol. 45, 2012, pp. 91-98.

[13] M. Lebram, H. Engström, H. Gustavsson, "A Driving Simulator Based on Video Game Technology," in Linköping Electronic Conference Proceedings, 2006, pp. 39-43.

[14] M. Cha, J. Yang, S. Han, "An Interactive Data-Driven Driving Simulator Using Motion Blending," in Computers in Industry, vol. 59, 2008, pp. 520-531.

[15] Y. Tang, X. Zhang, L. Li-hua, "Research on Driving Simulation System for Special Heavy Vehicle," in Audio Language and Image Processing (ICALIP), 2010, pp. 208-213.

[16] Turkish National Polis Traffic Services Department. (2013). 2013 Y1l Trafik İdari Para Ceza Rehberi [Online]. Available: http://www.trafik.gov.tr/Haberler/Sayfalar/2013_ceza.aspx.

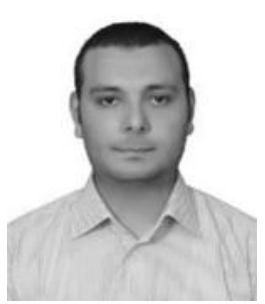

İ. ÖZTEL was born in Trabzon, Turkey, in 1988. He received his B.S. and M.S. degrees in Computer Engineering at Sakarya University, Sakarya, in 2011 and 2014, respectively. He is a Research Assistant in the Department of Computer Engineering, Sakarya University since 2012. His research interests include virtual reality and game programming.

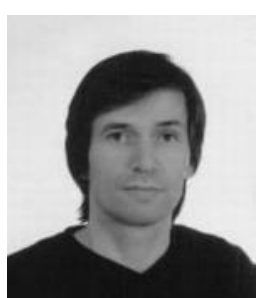

C. ÖZ was born in Cankiri, Turkey, in 1967. He received his B.S. degree in Electronics and Communication Engineering in 1989 from Yildız Technical University and his M.S. degree in Electronics and Computer Education in 1993 from Marmara University, Istanbul. During the M.S. studies, he worked as a lecturer in Istanbul Technical University. In 1994, he began his Ph.D. study in Electronics Engineering in Sakarya University. He completed his Ph.D. in 1998. He worked as a research fellow in University of Missouri-Rolla, MO, USA. He has been working as an associate professor in Computer and Information Sciences Faculty, Department of Computer Engineering in Sakarya University. His research interests include robotics, vision, artificial intelligence, virtual reality, and pattern recognition. 